\title{
Формирование и деформация капель жидкости в микроканалах
}

\author{
(C) Ф.В. Роньшин, Ю.А. Дементьев, Е.А. Чиннов \\ Институт теплофизики им. С.С. Кутателадзе СО РАН, Новосибирск, Россия \\ E-mail: f.ronshin@gmail.com
}

Поступило в Редакцию 21 апреля 2020г.

В окончательной редакции 21 апреля 2020г.

Принято к публикации 23 апреля 2020 г.

\begin{abstract}
Выполнено экспериментальное исследование закономерностей образования капель в узких горизонтальных микроканалах прямоугольного сечения с высотой от 50 до $150 \mu \mathrm{m}$. Показано, что в указанных каналах существует новый режим течения, когда по микроканалу движутся капли, представляющие собой вертикальные жидкостные перемычки. Выделено три механизма формирования таких капель: формирование непосредственно возле сопла жидкости, отрыв капель от жидкости, движущейся по боковым сторонам канала, и формирование капель вследствие разрушения сильно деформированных капель и горизонтальных жидкостных перемычек. Установлено, что деформация капель возрастает с увеличением числа Вебера. Показано, что при достижении первого критического значения числа Вебера капли начинают деформироваться, а при достижении второго - разрушаться.
\end{abstract}

Ключевые слова: микроканал, двухфазный поток, капли, режимы течения.

DOI: 10.21883/PJTF.2020.15.49742.18350

Исследования капельных течений в разных условиях широко представлены во многих публикациях. Например, в работах $[1,2]$ исследуются взаимодействие и разрушение капель в свободном потоке, что важно для развития технологий тушения пожаров. Спрейное, капельное и струйное охлаждение активно используется в таких отраслях промышленности, как металлургия, энергетика, химическая и пищевая промышленность, аэрокосмическая отрасль и т.д. [3]. Все большее внимание уделяется капиллярной гидродинамике и теплообмену в микросистемах, что связано с развитием электроники и медицины и общей тенденцией миниатюризации устройств, в частности, в аэрокосмической отрасли, транспорте и энергетике.

Исследования, посвященные режимам двухфазного течения в микроканалах различной геометрии, были рассмотрены в обзорах [4,5]. Образование капель жидкости наблюдалось при переходе от кольцевого к капельнокольцевому режиму при высоких скоростях газа (выше $10-20 \mathrm{~m} / \mathrm{s})$. В частности, это явление изучалось в горизонтальных прямоугольных каналах толщиной $1 \mathrm{~mm}$ [6] и вертикальных трубках диаметром свыше $1 \mathrm{~mm}[7]$.

В более узких горизонтальных микроканалах мелкие капли на нижней стенке канала были обнаружены при малых приведенных скоростях жидкости в снарядном, прерывистом и струйном режимах течения [8]. Подобное явление в случае снарядного режима наблюдалось в работе [9] для вертикального прямоугольного канала толщиной $0.3 \mathrm{~mm}$. С уменьшением высоты микроканала в двухфазном течении начинают формироваться капли жидкости, представляющие собой вертикальные жидкостные перемычки между верхней и нижней стенками микроканала, а также сидячие капли на стенках мик- роканала. Исследование режимов течения двухфазного потока и образования капель в узких горизонтальных каналах прямоугольного сечения с высотой $100 \mu \mathrm{m}$ и более представлено в работе [8]. Впервые показано, что в указанных каналах существуют режимы течения, в которых происходит образование капель при малых значениях приведенных скоростей жидкости и газа. Подробное экспериментальное исследование течения газоводяного потока в коротком горизонтальном канале прямоугольного поперечного сечения высотой от 100 до $500 \mu \mathrm{m}$ и шириной 9-40 mm выполнено в [10].

Однако в предыдущих исследованиях регистрировались только факты возникновения капель в изучаемых режимах для разных каналов. В настоящей работе приведены результаты новых опытов в микроканалах прямоугольного сечения с высотой 100 и $150 \mu \mathrm{m}$ и впервые выполнен анализ данных по изменению размеров капель, их деформации и разрушению.

Экспериментальная установка состоит из сменных микроканалов и подводов жидкости и газа. Газ подается в центральную часть микроканала. Расход газа регулируется в интервале от 100 до $10000 \mathrm{ml} / \mathrm{min}$ и поддерживается постоянным при помощи регулятора расхода El-Flow фирмы Bronkhorst. Расход жидкости изменяется в интервале от 0.5 до $100 \mathrm{ml} / \mathrm{min}$ при помощи высокоточного шприцевого насоса Cole-Parmer EW-74905-54. Жидкость вводится в микроканал через вход для жидкости, расположенный под углом $11^{\circ}$ к плоскости микроканала. Расстояние между газовым и жидкостным соплом составляет около $70 \mathrm{~mm}$. Давление в газовой камере измеряется датчиком давления WIKA Туре Р-30. Данные с датчика давления и текущий расход газа записываются в файл на персональном компьютере. Описание экспериментальной установки, устройства 


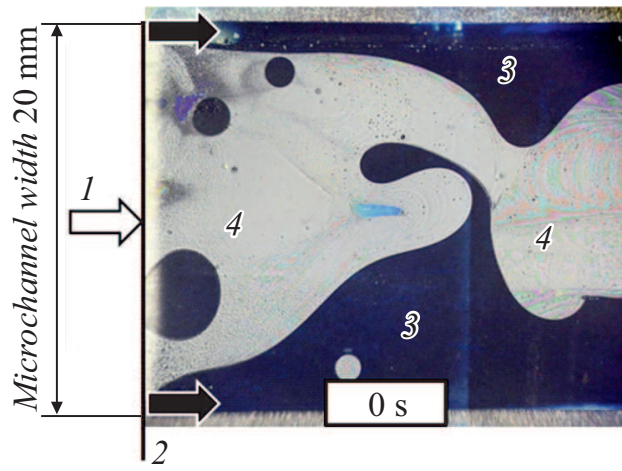

$b$

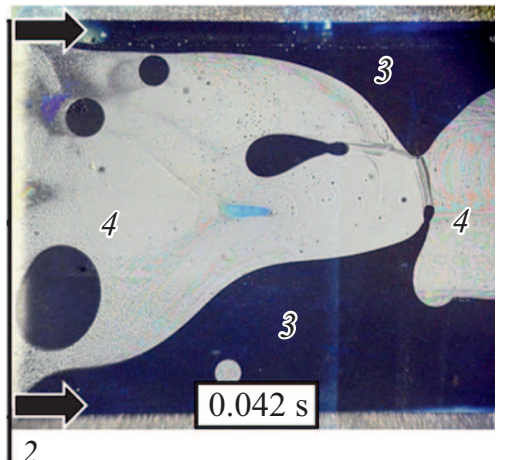

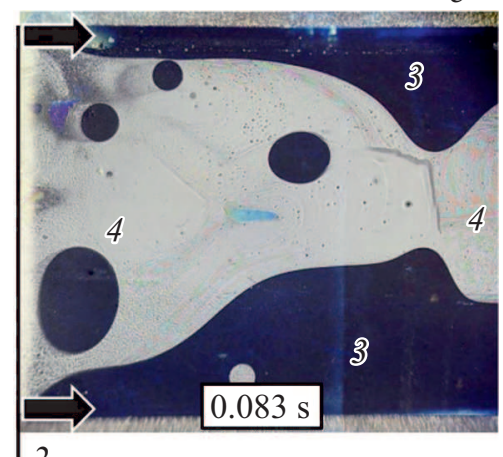

2

Рис. 1. Шлирен-фотографии подвижных капель жидкости в канале сечением $0.15 \times 20 \mathrm{~mm}$ при $U_{S G}=2.78 \mathrm{~m} / \mathrm{s}, U_{S L}=0.0056 \mathrm{~m} / \mathrm{s}$ в зависимости от времени (вид сверху). Жидкость - FC-72, газ - азот. 1 - вход газа в микроканал, 2 - щель в нижней стенке микроканала для входа жидкости, 3 - жидкость, 4 - газ. Светлая стрелка - направление движения газа, темные стрелки направления движения жидкости.

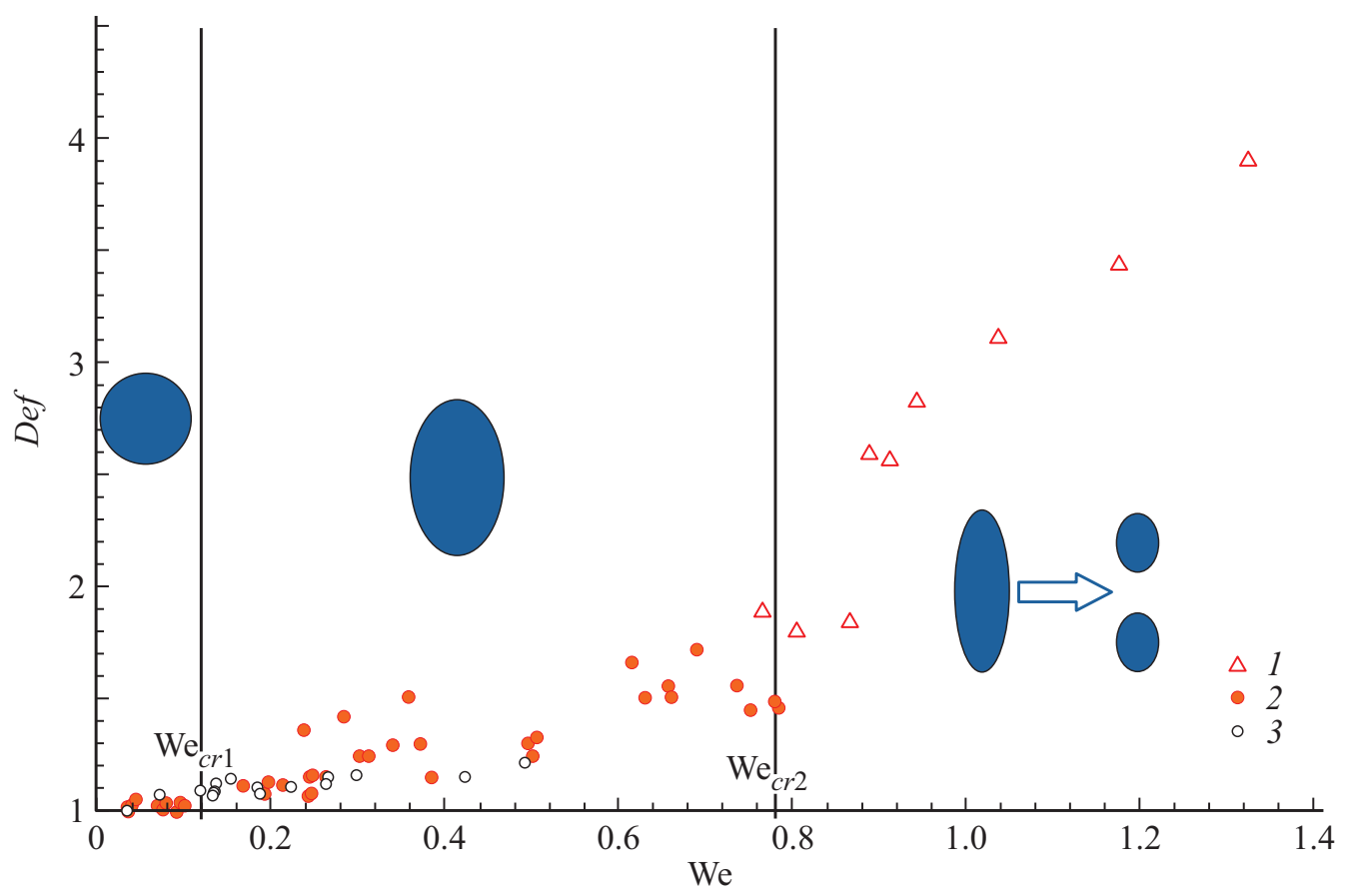

Рис. 2. Деформация и разрушение капель жидкости в зависимости от числа Вебера. 1 - микроканал сечением $0.15 \times 20 \mathrm{~mm}$, FC-72, область разрушения капель; 2 - микроканал сечением $0.15 \times 20 \mathrm{~mm}$, FC-72, область деформации капель; $3-$ микроканал сечением $0.1 \times 30 \mathrm{~mm}$, вода, область деформации капель.

микроканала и используемой для регистрации режимов двухфазного течения и характеристик капель модификации шлирен-метода представлено в работе [11]. В качестве рабочих использовались следующие жидкости: очищенная вода фирмы Milli-Q и FC-72 [12].

Выполнено исследование формирования капель в горизонтальных микроканалах сечением $0.1 \times 30$ и $0.15 \times 20 \mathrm{~mm}$. Капли представляли собой вертикальные перемычки между пленками жидкости, расположенными на нижней и верхней сторонах канала. В канале высотой $100 \mu \mathrm{m}$ при использовании в качестве рабочей жидкости воды такие перемычки наблюдаются в широком диа- пазоне расходов газа и жидкости. Обнаружено, что в условиях хорошей смачиваемости (жидкость FC-72) такие вертикальные жидкостные перемычки формируются в каналах высотой $150 \mu \mathrm{m}$.

В канале высотой $150 \mu \mathrm{m}$ и шириной $20 \mathrm{~mm}$ при использовании в качестве рабочей жидкости FC-72 капли формируются даже при небольших расходах жидкости. На рис. 1 показано, как происходит формирование капель жидкости при следующих приведенных скоростях жидкости и газа: $U_{S G}=2.78 \mathrm{~m} / \mathrm{s}, U_{S L}=0.0056 \mathrm{~m} / \mathrm{s}$. Приведенные скорости газа $U_{S G}$ и жидкости $U_{S L}$ определялись как объемный расход газа или жидкости, де- 


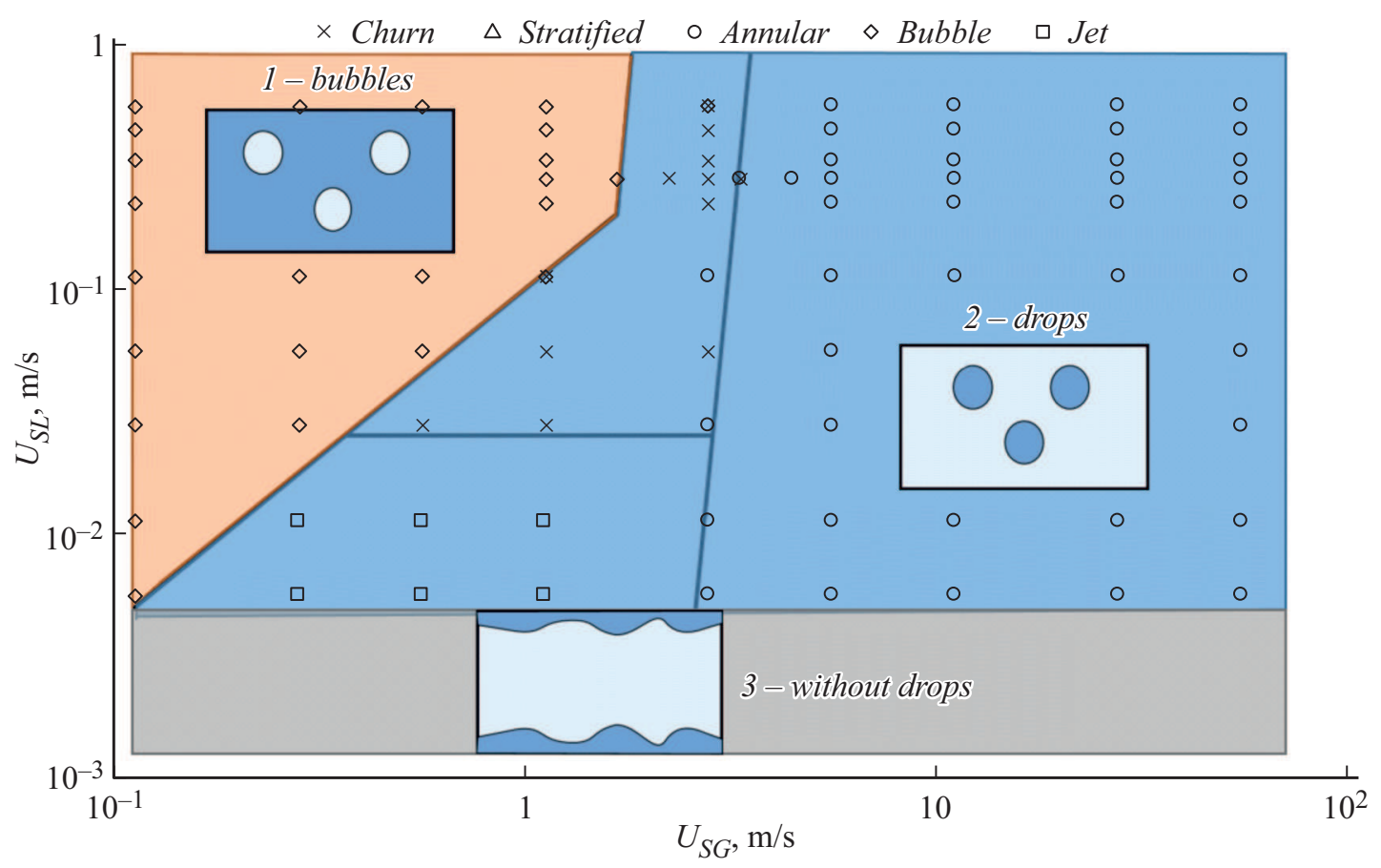

Рис. 3. Режимы течения в микроканале сечением $0.15 \times 20 \mathrm{~mm}$. Жидкость - FC-72, газ - азот.

ленный на площадь поперечного сечения канала. Можно выделить три механизма. Первый - формирование капель непосредственно возле жидкостного сопла. В этом случае капли имеют форму, близкую к кругу (если рассматривать их плоскими), но их размер может различаться. Второй механизм - это формирование капель непосредственно в самом канале, когда капля отделяется от жидкости, движущейся по боковым сторонам канала, а затем капля приобретает правильную форму. Третий механизм реализуется, когда капли формируются вследствие разрушения горизонтальных жидкостных перемычек. Диаметр капель в таком режиме изменяется от 1 до $10 \mathrm{~mm}$. При увеличении расхода газа интенсивность формирования капель возрастает, а их размеры уменьшаются. Наблюдаются капли диаметром менее $0.5 \mathrm{~mm}$. При $U_{S L}=0.0056 \mathrm{~m} / \mathrm{s}$ и $U_{S G}=0.28 \mathrm{~m} / \mathrm{s}$ средний диаметр капель составляет $7 \mathrm{~mm}$. При увеличении приведенной скорости газа до $U_{S G}=1.11 \mathrm{~m} / \mathrm{s}$ средний диаметр капель уменьшается до $3 \mathrm{~mm}$. С увеличением приведенной скорости жидкости частота формирования капель уменьшается, так как бо́льшая часть жидкости движется вдоль боковых стенок микроканала, формируются горизонтальные перемычки жидкости сложной конфигурации.

При небольших значениях деформации капли имеют эллипсоидальную форму. Проведено исследование деформации капель жидкости $D e f=a / b$, где $a$ - максимальный диаметр капли, а $b-$ минимальный, в зависимости от числа Вебера газа We $=\rho D U_{M}^{2} / \sigma$. Здесь $\rho-$ плотность газа, $D=\sqrt{a b}-$ эквивалентный диаметр, $U_{M}=U_{S L}+U_{S G}-$ скорость смеси, а $\sigma-$ поверхност- ное натяжение. Значения деформации капель жидкости в зависимости от числа Вебера представлены на рис. 2. Определено критическое число Вебера $\mathrm{We}_{c r 1}=0.12$, при котором деформация капли не превышает величину 1.1. При увеличении значения числа We деформация капель возрастает, значение деформации не превышает 1.8. При достижении числа Вебера $\mathrm{We}_{c r 2}=0.78$ деформация капель становится настолько большой, что растет со временем, капля меняет форму и разрушается, образуя, как правило, две капли меньшего размера. В данном случае деформация капель определялась в последний момент, когда они имели эллипсоидальную форму. Таким образом, можно выделить три диапазона эволюции капель (круглые капли, деформация капель и разрушение капель), которые представлены на рис. 2.

На основании полученных данных можно предложить новую классификацию режимов двухфазного течения в микроканалах, которая схематически представлена на рис. 3: 1 - пузырьковый режим, когда по микроканалу движутся пузырьки газа; 2 - капельный режим, когда в классических режимах течения наблюдается движение капель жидкости, представляющих собой вертикальные жидкостные перемычки, 3 - классические режимы течения, когда капли не образуются. При этом область капельного режима течения существенно зависит от высоты канала и смачиваемости поверхности. При использовании воды в качестве рабочей жидкости капли впервые появляются в микроканале высотой $440 \mu \mathrm{m}$ [8] только при высоких расходах газа. При уменьшении высоты канала интенсивность образования капель возрастает. В канале высотой $50 \mu \mathrm{m}$ такие капли формируются 
во всем диапазоне расходов газа и жидкости. В условиях хорошей смачиваемости в канале высотой $150 \mu \mathrm{m}$ (жидкость FC-72, угол смачивания $\theta=12^{\circ}$ ) капли жидкости наблюдаются во всем диапазоне расходов газа и жидкости, когда как при использовании воды в качестве рабочей жидкости с углом смачивания $\theta=106^{\circ}$ такие капли наблюдаются только при высоких расходах газа в раздельном и кольцевом режимах. При использовании водно-спиртового раствора $\left(\theta=58^{\circ}\right)$ область капельного режима существенно возрастает [12].

Можно заключить, что детально исследован новый режим течения, когда по микроканалу движутся капли, представляющие собой вертикальные жидкостные перемычки. Выделено три механизма формирования таких капель: формирование непосредственно возле сопла жидкости, отрыв капель от жидкости, движущейся по боковым сторонам канала, и формирование капель вследствие разрушения сильно деформированных капель и горизонтальных жидкостных перемычек. Показано, что такие капли начинают деформироваться при увеличении расходов газа и жидкости. С увеличением числа Вебера по газу величина деформаций возрастает. Существует критическое значение числа Вебера, когда значение деформации становится настолько большим, что капли начинают разрушаться. Предложена новая классификация режимов течений: 1) пузырьковый режим, когда по микроканалу движутся пузырьки газа; 2) капельный режим, когда на фоне традиционных режимов течения (вспененного, струйного и кольцевого) наблюдается движение капель жидкости, представляющих собой вертикальные жидкостные перемычки; 3) раздельный режим течения (при малых расходах жидкости), когда капли не образуются.

\section{Финансирование работы}

Исследование выполнено за счет гранта Российского научного фонда (соглашение № 18-19-00407).

\section{Конфликт интересов}

Авторы заявляют, что у них нет конфликта интересов.

\section{Список литературы}

[1] Кузнецов Г.В., Волков Р.С., Стрижсак П.А. // Письма в ЖТФ. 2015. Т. 41. В. 17. С. 53-60.

[2] Кузнещов Г.В., Стрижак П.А. // Письма в ЖТФ. 2019. T. 45 . B. 6. C. $23-26$.

[3] Nazarov A.D., Miskiv N.V., Surtaev A.S., Serdyukov V.S. // J. Eng. Thermophys. 2019. V. 28. N 4. P. 489-498.

[4] Ребров Е.В. // Теорет. основы хим. технологии. 2010. Т. 44. № 4. C. $371-383$.

[5] Чиннов Е.А., Роньшин Ф.В., Кабов О.А. // Теплофизика и аэромеханика. 2015. Т. 22. № 3. С. 275-297.

[6] Kabov O.A., Chinnov E.A., Cheverda V. // Microgravity Sci. Technol. 2007. V. 19. N 3/4. P. 44-47.
[7] Mishima K., Hibiki T. // Int. J. Multiphase Flow. 1996. V. 22. N 4. P. 703-712.

[8] Чиннов Е.А., Кабов О.А. // Письма в ЖТФ. 2011. Т. 37. B. 14. C. $47-53$.

[9] Xu J.L., Cheng P., Zhao T.S. // Int. J. Multiphase Flow. 1999. V. 25. N 3. P. 411-432.

[10] Chinnov E.A., Ron'shin F.V., Kabov O.A. // Int. J. Multiphase Flow. 2016. V. 80. P. 57-68.

[11] Ronshin F.V., Chinnov E.A. // Exp. Thermal Fluid Sci. 2019. V. 103. P. 262-273.

[12] Роньшин Ф.В., Чеверда В.В., Чиннов Е.А., Кабов О.А. // Письма в ЖТФ. 2018. Т. 44. В. 7. С. 69-77. 